\title{
Outcomes and emergency medical services resource utilization among patients with syncope arriving to the emergency department by ambulance
}

\author{
Lawrence Yau, BMSc ${ }^{*}$; Muhammad A. Mukarram, MBBS, $\mathrm{MPH}^{\dagger}$; Soo-Min Kim, $\mathrm{BScH}^{\dagger}$; \\ Kirtana Arcot, $\mathrm{MSc}^{\dagger}$; Kednapa Thavorn, MPharm, $\mathrm{PhD}^{\dagger \ddagger \S}$; Ian G. Stiell, MD, MSc ${ }^{\dagger \neq ף ;}$ \\ Monica Taljaard, PhD ${ }^{\dagger \neq}$; Brian H. Rowe, MD, MSc ${ }^{* *}$; Marco L. A. Sivilotti, MD, MSc ${ }^{\dagger \dagger \ddagger \ddagger}$; \\ Venkatesh Thiruganasambandamoorthy, MBBS, MSc ${ }^{\dagger \neq \pi}$
}

\begin{abstract}
CLINICIAN'S CAPSULE
What is known about the topic?

A majority of syncope patients are transported to the emergency department by emergency medical services (EMS), yet only a small proportion are admitted or suffer serious adverse events (SAE).

What did this study ask?

What proportion of EMS syncope patient transports are at low risk (i.e., absence of EMS interventions, hospitalization, and SAE)?

What did this study find?

This prospective cohort study found that $40 \%$ of syncope transports are at low risk.

Why does this study matter to clinicians?

This group of patients represents potentially avoidable transports once a clinical decision tool is developed with a substantial opportunity cost for EMS systems.
\end{abstract}

\section{ABSTRACT}

Objective: Syncope accounts for $1 \%$ of emergency department (ED) visits, yet few experience a serious adverse event (SAE). Two-thirds of syncope patients are transported to the ED by ambulance, placing considerable burden on emergency medical services (EMS), and many of these transports may be unnecessary. We estimated the proportion of syncope patients who fell into a low-risk category based on an ED diagnosis of vasovagal syncope and the absence of EMS intervention, hospitalization, or SAE.

Methods: We conducted a multicentre prospective cohort study enrolling adult syncope patients transported to the ED by ambulance over 13 months. We collected demographics and EMS interventions, and followed patients for 30 days to identify all SAE, including death, dysrhythmia, myocardial infarction, aortic dissection, pulmonary embolism, subarachnoid hemorrhage, significant hemorrhage, and related procedural interventions.

Results: Of 990 (67.2\%) patients transported to the ED by ambulance, 121 had EMS interventions, 137 suffered 30-day $\mathrm{SAE}, 393(39.7 \% ; 95 \% \mathrm{Cl} 36.6,42.8)$ were deemed low risk, 41 patients with vasovagal syncope were lost to follow-up, and 298 patients were diagnosed with non-vasovagal syncope. During transport, $121(12.2 \% ; 95 \% \mathrm{Cl} 10.2,14.3)$ patients underwent some EMS intervention, and $137(14.6 \% ; 95 \% \mathrm{Cl}$ $12.4,16.9)$ suffered SAEs within 30 days.

Conclusion: About $40 \%$ of patients transported to the ED by ambulance are at low risk and may not benefit from paramedic care or transport to a hospital. A robust clinical decision tool would help identify patients safe for treat-andrelease, diversion to alternative care, or rapid offload into lowacuity ED areas, potentially reducing EMS workload and cost.

\section{RÉSUMÉ}

Objectif: Les syncopes motivent $1 \%$ des consultations au service des urgences (SU), mais le malaise entraîne peu d'événements indésirables graves (EIG). Ainsi, deux tiers des patients ayant subi une syncope sont transportés en ambulance au SU, ce qui impose un lourd fardeau sur les services médicaux d'urgence (SMU), et pourtant bon nombre de transports effectués seraient non nécessaires. Aussi l'étude visait-elle à estimer la proportion de patients ayant subi une syncope dont l'état serait jugé à faible risque d'après le diagnostic de syncope vasovagale posé au SU ainsi que

From the * Faculty of Medicine, University of Ottawa, Ottawa, ON; † Ottawa Hospital Research Institute, Ottawa, ON; $\ddagger$ School of Epidemiology, Public Health and Preventive Medicine, University of Ottawa, Ottawa, ON; § Institute of Clinical Evaluative Sciences, Ottawa, ON; ๆ Department of Emergency Medicine, University of Ottawa, Ottawa, ON; ** Department of Emergency Medicine and School of Public Health, University of Alberta, Edmonton, AB; †† Department of Emergency Medicine, Queen's University, Kingston, ON; and $\neq \ddagger$ Department of Biomedical and Molecular Sciences, Queen's University, Kingston, ON

Correspondence to: Venkatesh Thiruganasambandamoorthy, Clinical Epidemiology Unit, F6, 1053 Carling Avenue, Ottawa, ON K1Y 4E9; Email: vthirug@ohri.ca 
d'après l'absence d'intervention faite par les SMU, d'hospitalisation ou d'EIG.

Méthode: II s'agit d'une étude prospective de cohortes, multicentrique, menée chez des adultes qui ont subi une syncope et qui ont été transportés en ambulance au SU, sur une période de 13 mois. Ont été recueillies des données démographiques ainsi que les notes sur les interventions effectuées par les SMU; à cela s'ajoute un suivi de 30 jours aux fins de collecte de renseignements sur tout EIG : mort, arythmie, infarctus du myocarde, dissection de l'aorte, embolie pulmonaire, hémorragie sous-arachnoïdienne, hémorragie importante et gestes interventionnels liés aux troubles en question.

Résultats: Au total, 990 patients $(67,2 \%)$ ont été transportés en ambulance au SU; sur ce nombre, 121 ont subi des interventions pratiquées par les SMU; 137 ont connu un EIG au cours des 30 jours suivant le malaise; 393 (39,7\%; IC à $95 \%: 36,6-42,8)$ ont été jugés à faible risque; 41 ayant fait une syncope vasovagale ont été perdus de vue durant le suivi; et
298, ont fait une syncope non vasovagale. Durant le transport, 121 patients $(12,2 \%$; IC à $95 \%: 10,2-14,3)$ ont subi une forme quelconque d'intervention par les SMU et, au cours des 30 jours de suivi, 137 (14,6\%; IC à $95 \%$ : 12,4-16,9) ont connu un EIG.

Conclusion: Environ $40 \%$ des patients transportés en ambulance au SU connaissent un faible risque et, dans leur cas, la prestation de soins paramédicaux ou le transport à I'hôpital pourraient ne pas être nécessaires. Un outil d'aide à la décision clinique qui soit digne de confiance pourrait faciliter le repérage des patients dont l'état se prêterait au traitement suivi du congé, à une orientation vers d'autres types de soins ou à un passage rapide dans des zones de petites urgences, ce qui permettrait à la fois de réduire la charge de travail des SMU ainsi que les coûts.

Keywords: clinical decision aid, emergency department, emergency medical services, prehospital, resource utilization, severe adverse events, syncope

\section{INTRODUCTION}

Syncope, defined as a sudden transient loss of consciousness followed by spontaneous complete recovery, accounts for $\sim 1 \%$ of all North American emergency department (ED) visits. ${ }^{1,2}$ A recent Canadian study showed that $70 \%$ of syncope patients arrived by ambulance, ${ }^{3}$ but only $17 \%$ were admitted and $9.7 \%$ suffered serious adverse events (SAE) within 30 days. This discrepancy between the number transported and the proportion hospitalized or suffering an SAE suggests that many syncope patients are at low risk and may not benefit from emergency medical services (EMS) care.

In modern EMS systems, paramedics assess patients at the scene, transport them to increasingly crowded EDs, and endure offload delays until ED stretchers are available. In some jurisdictions, treat-and-release protocols for conditions like hypoglycemia and supraventricular tachycardia allow EMS providers to assess and discharge select patients without transporting them. ${ }^{4}$ Although the likelihood of SAE is higher in syncope, a validated decision tool, which does not yet exist, could reduce EMS transports and enable low-risk diversion to more appropriate care settings.

Our objective was to estimate the proportion of syncope patients transported to the ED by ambulance who are at low risk based on an ED diagnosis of vasovagal syncope and the absence of EMS intervention, hospitalization, and SAE at 30 days. We also sought to describe EMS interventions in this cohort.

\section{METHODS}

\section{Setting and patients}

This prospective cohort study, a substudy of the RiskStratification of adult ED Syncope (RiSEDS) study, was conducted at five large Canadian EDs (Ottawa Hospital Civic and General campuses - Ottawa, ON; Kingston General Hospital and Hotel Dieu - Kingston, ON; University of Alberta Hospital - Edmonton, $\mathrm{AB}$ ) from February 2012 to February 2013..$^{5}$ Patient demographics, medical history, and disposition were collected within the RiSEDS study, along with EMSidentified SAE, EMS interventions, and ED diagnosis. ED physicians screened consecutive patients presenting with syncope, pre-syncope, fainting, blackout, loss of consciousness, fall, collapse, seizure, and dizziness or light-headedness. Patients $\geq 16$ years of age who met the definition of syncope and were transported to the ED by ambulance were eligible. Previously enrolled patients and those with any of the following were excluded: pre-syncope, persistent altered mental status, alcohol or drug intoxication, witnessed seizure, or loss of consciousness following head trauma. Patients whose syncope caused a head injury were included, but those who sustained major trauma requiring hospitalization were excluded because of difficulty determining whether outcomes were due to syncope or trauma. The Hospital Research Ethics Boards approved the study without requirement for written consent. 


\section{Outcome measures}

We defined "low-risk" syncope patients as those who received no EMS intervention, were discharged from the ED with a diagnosis of vasovagal syncope, and experienced no SAE within 30 days. EMS interventions were identified in EMS call reports, hospitalizations based on hospital records, and final ED diagnosis was a specific field on the RiSEDS data form. We conducted 30-day telephone follow-up to identify other healthcare visits, new diagnoses, interventions, and SAEs.

SAEs included any of the following within 30 days as per published reporting guidelines: death, dysrhythmia, myocardial infarction, serious structural heart disease, aortic dissection, pulmonary embolism, severe pulmonary hypertension, subarachnoid hemorrhage, significant hemorrhage, or procedural interventions to treat a cause of syncope.

\section{Analysis}

Means and standard deviations (SD) are reported to describe continuous variables and frequencies with proportions for dichotomous variables. Sample size was based on the larger RiSEDS study. ${ }^{6}$

\section{RESULTS}

Figure 1 shows that ED physicians at five study sites enrolled 1,473 patients with true syncope: 990 (67.2\%) were transported to the ED by ambulance, and 54 patients $(5.5 \%)$ were lost to follow-up. Of these (see

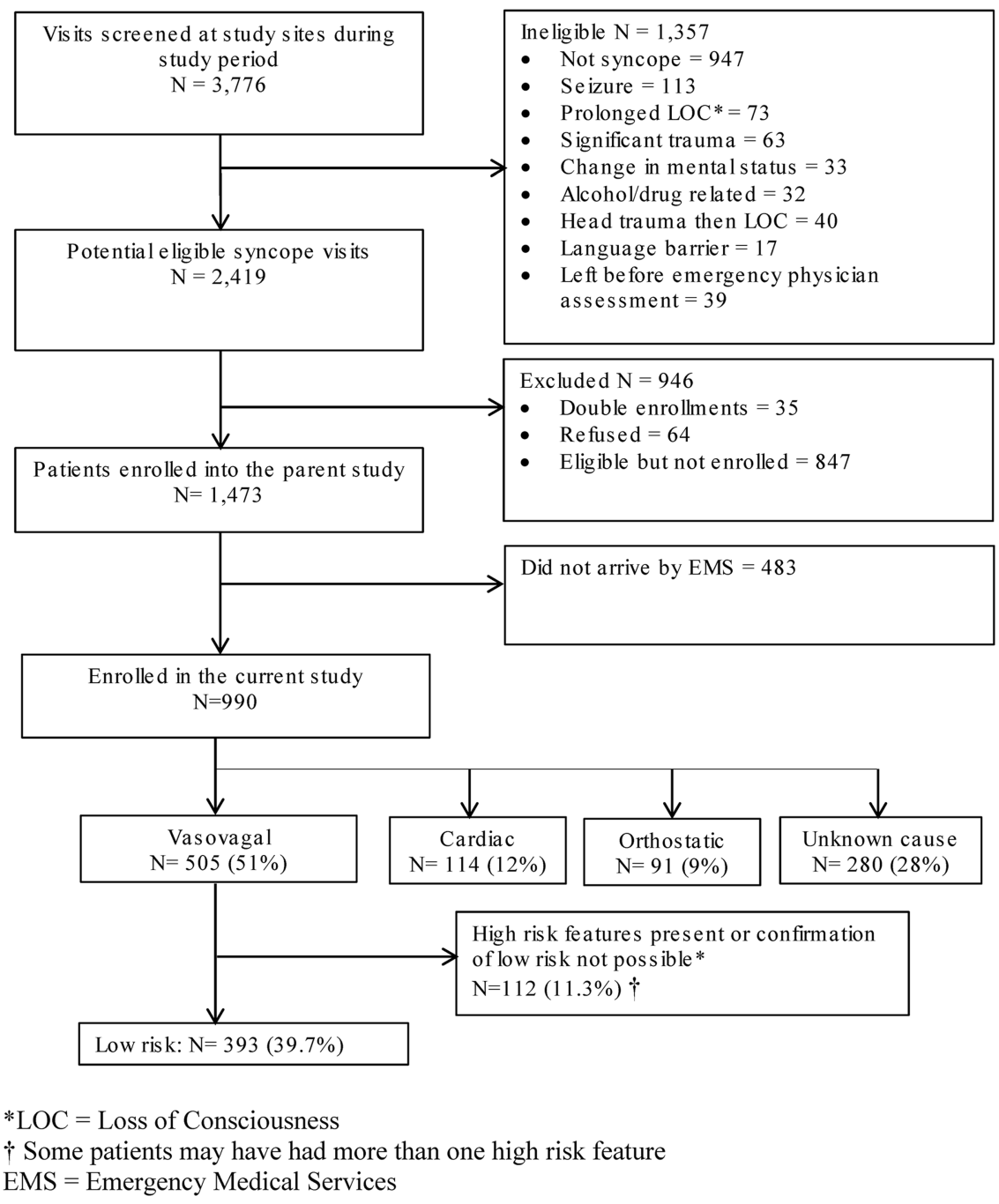

Figure 1. Selection of patients for the study. 
Figure 1/Appendix A), 505 (51\%) had vasovagal syncope, and, after exclusion of 41 patients with no 30-day follow-up data, 393 (39.7\%; 95\% CI 36.6, 42.8) were at low-risk - potentially appropriate for alternative management based on their diagnosis and the absence of EMS intervention, hospitalization, or 30-day SAE.

Table 1 shows that mean age was 58.9 years (SD, $23.1)$ and 543 patients $(54.9 \%)$ were female. The most common ED diagnosis was vasovagal syncope $(51.0 \%)$ and 166 patients $(16.8 \%)$ were hospitalized during the index visit. Paramedics provided one or more interventions for 121 patients (12.2\%). One underwent transcutaneous pacing, and 38 received cardiac medications, including acetylsalicylic acid (ASA) or aspirin $(n=20)$, nitroglycerine $(n=13)$, atropine $(n=4)$, and metoprolol $(\mathrm{n}=1)$. Sixty-two received symptom-relief medications, including dimenhydrinate $(n=41)$, morphine $(n=9)$, metoclopramide $(n=4)$, ondansetron $(\mathrm{n}=3)$, fentanyl $(\mathrm{n}=3)$, ketorolac $(\mathrm{n}=1)$, and diphenhydramine $(n=1)$. Seventeen received glucose for suspected hypoglycemia, and 1 received midazolam for a suspected seizure (although physicians subsequently confirmed that all suffered true syncope). Thirty underwent spinal or extremity immobilization for injuries.
Table 2 shows that $137(14.6 \%$; 95\%CI $12.4,16.9)$ patients suffered an SAE within 30 days. Of these, 32 (3.4\%) were detected by EMS, 58 (6.2\%) during ED evaluation, and $47(5.0 \%)$ within 30 days of ED disposition. SAEs included 9 (0.9\%) deaths, 63 (6.7\%) dysrhythmias, 32 (2.9\%) other cardiac outcomes, and $35(3.5 \%)$ non-cardiac events.

\section{DISCUSSION}

\section{Limitations}

Patients were recruited from large urban EDs and their affiliated EMS systems, and our findings may not generalize to other practice settings. Emergency physicians did not complete study forms for 847 eligible syncope patients; however, these were of similar age and gender to those enrolled, suggesting selection bias is unlikely. Fifty-three patients were lost to follow-up, but they were younger (mean age, 43.6), more often vasovagal $(77.4 \%)$, and none were hospitalized during their index visit, making them a lower-risk group. Study diagnoses were based on discharge diagnoses documented by ED physicians, and it is unclear whether an EMS provider could achieve similar diagnostic

\begin{tabular}{lcc|}
\hline Table 1. Patient characteristics $(\mathbf{N}=\mathbf{9 9 0})$ & & \\
\hline & Low risk: N (\%) & Non-low risk: N (\%) \\
\hline Number of patients & 393 & 597 \\
Mean age in years (SD) & $52.4(23.2)$ & $63.2(22.2)$ \\
Female sex & $236(60.1)$ & $307(51.4)$ \\
Cardiac history & & \\
Coronary artery disease & $26(6.6)$ & $113(18.9)$ \\
Valvular heart disease & $7(1.8)$ & $56(9.4)$ \\
Congestive heart failure & $7(1.8)$ & $32(5.4)$ \\
Atrial fibrillation/flutter & $6(1.5)$ & $25(4.2)$ \\
Pacemaker & $5(1.3)$ & $23(3.9)$ \\
Cardiomyopathy & $1(0.3)$ & $7(1.2)$ \\
Ventricular arrhythmia & $1(0.3)$ & $6(1.0)$ \\
Hypertension & $119(30.3)$ & $73(12.2)$ \\
Previous syncope & $47(12.0)$ & $87(14.6)$ \\
Diabetes & $26(6.6)$ & $59(9.9)$ \\
Cerebrovascular disease & $30(7.6)$ & $13(2.2)$ \\
Seizure disorder & $5(1.3)$ & $122(27.4)$ \\
Systolic BP: mean (SD) & $120(24.8)$ & $79(21.6)$ \\
Heart rate: mean (SD) & $80(17.8)$ & $17(3.2)$ \\
Respiratory rate: mean (SD) & $17(2.9)$ & $97(4.1)$ \\
Oxygen saturation: mean (SD) & $98(2.8)$ & $166(27.8)$ \\
Hospitalized at index visit & $0(0.0)$ & \\
BP=blood pressure; SD = standard deviation. & & \\
& &
\end{tabular}


EMS-transported syncope patients: outcomes and resource utilization

\begin{tabular}{|c|c|c|c|c|}
\hline Event and where detected: N (\%) & By EMS & In ED & After ED & Total \\
\hline Cardiac dysrhythmia & $27(2.9)$ & $24(2.6)$ & $12(1.3)$ & $63(6.7)$ \\
\hline Sinus pause & $2(0.2)$ & $9(1.0)$ & $4(0.4)$ & $15(1.6)$ \\
\hline Atrial fibrillation & $5(0.5)$ & $6(0.6)$ & $3(0.3)$ & $14(1.5)$ \\
\hline Complete heart block & $5(0.5)$ & $5(0.5)$ & $1(0.1)$ & $11(1.2)$ \\
\hline Sinus bradycardia & $6(0.6)$ & $0(0.0)$ & $1(0.1)$ & $7(0.7)$ \\
\hline Mobitz II block & $5(0.5)$ & $1(0.1)$ & $0(0.0)$ & $6(0.6)$ \\
\hline Torsades des pointes & $2(0.2)$ & $0(0.0)$ & $2(0.2)$ & $4(0.4)$ \\
\hline Supraventricular tachycardia & $1(0.1)$ & $2(0.2)$ & $1(0.1)$ & $4(0.4)$ \\
\hline Asystole & $1(0.1)$ & $0(0.0)$ & $0(0.0)$ & $1(0.1)$ \\
\hline Sick sinus syndrome & $0(0.0)$ & $1(0.1)$ & $0(0.0)$ & $1(0.1)$ \\
\hline Myocardial infarction & $0(0.0)$ & $10(1.1)$ & $3(0.3)$ & $13(1.4)$ \\
\hline Serious structural heart disease & $0(0.0)$ & $6(0.6)$ & $5(0.5)$ & $11(1.2)$ \\
\hline Pacemaker insertion & $0(0.0)$ & $0(0.0)$ & $6(0.6)$ & $6(0.6)$ \\
\hline Aortic dissection & $0(0.0)$ & $1(0.1)$ & $1(0.1)$ & $2(0.2)$ \\
\hline \multicolumn{5}{|l|}{ Non-cardiac SAE } \\
\hline Significant hemorrhage & $5(0.5)$ & $7(0.7)$ & $3(0.3)$ & $15(1.6)$ \\
\hline Pulmonary embolism & $0(0.0)$ & $3(0.3)$ & $3(0.3)$ & $6(0.6)$ \\
\hline Subarachnoid hemorrhage & $0(0.0)$ & $2(0.2)$ & $0(0.0)$ & $2(0.2)$ \\
\hline Severe pulmonary hypertension & $0(0.0)$ & $0(0.0)$ & $1(0.1)$ & $1(0.1)$ \\
\hline Other ${ }^{*}$ & $0(0.0)$ & $5(0.5)$ & $6(0.6)$ & $11(1.2)$ \\
\hline Death $^{\dagger}$ & $0(0.0)$ & $0(0.0)$ & $9(0.9)$ & $9(0.9)$ \\
\hline Total & $32(3.4)$ & $58(6.2)$ & $47(5.0)$ & $137(14.6)$ \\
\hline
\end{tabular}

differentiation based on limited information available at the scene.

Although we identified a large opportunity cost for EMS systems, with $40 \%$ of syncope transports being potentially avoidable, we did not conduct a formal economic evaluation. Future studies should conduct cost-benefit analyses and examine the potential impact of a clinical decision tool, particularly on offload delays.

\section{CONCLUSION}

We found that $40 \%$ of syncope patients transported to the ED by ambulance are at low risk, representing a substantial target for avoidable EMS transports and an opportunity for resource conservation. These patients had vasovagal syncope, did not require EMS intervention or hospitalization, and did not experience an SAE within 30 days. Our findings, consistent with other studies, ${ }^{3,6-9}$ suggest the need for a decision tool to identify low-risk patients unlikely to benefit from EMS transport who are candidates for diversion to alternative care settings or rapid offload to low-acuity ED care locations. Such a tool could reduce EMS workload and cost, mitigate offload delays, and improve the utilization of an increasingly precious resource - the monitored ED stretcher.

The Ontario government recently proposed legislation to expand paramedic scope of practice, allowing non-ED options such as primary or community-based care. ${ }^{10}$ Our findings suggest that syncope represents an important candidate condition for an EMS treat-andrelease or treat-and-refer protocols; however, these must be accurate and sensitive enough to identify a small number of patients who might experience shortterm serious outcomes. Such pathways might involve urgent follow-up by a family physician or rapid access clinic, and presupposes accessibility of such care. However, additional work is needed to determine whether a decision rule is feasible and can be reliably incorporated into EMS practice.

Acknowledgements: We gratefully acknowledge all of the emergency physicians at The Ottawa Hospital - Civic and the General campuses, Kingston Health Sciences Centre, and University of Alberta Hospital who recruited the patients and the emergency medicine residents who helped in this process. We also gratefully acknowledge the emergency medical services providers and organizations (Regional Paramedic Program for Eastern 
Ontario, Emergency and Transportation Services - County of Frontenac, and Emergency Medical Services - Alberta Health Services) for providing the Ambulance Call Reports. We also thank the following members of our research team: Ottawa site Pam Ladouceur, RN; Sarah Gaudet, RN; Karen Pratt, RN; Dr. Aparna Vaidyanathan, MBBS; Soo-Min Kim, BScH; My-Linh Tran; Sheryl Domingo; and Angela Marcantonio; Kingston site Jane Reid, RN; Vi Ho, MD; Laura Goodfellow, R; and Vlad Latiu, MD; and Edmonton site - Justin Lowes, BSc; Danielle DeVuyst, RN; Pamela Pang, RN; and Natalie Runham, RN.

Funding: This study was supported by Physicians' Services Incorporated Foundation, Canadian Institutes of Health Research and Ontario Innovation Fund for Academic Health Sciences Centres of Ontario through The Ottawa Hospital Academic Medical Organization (TOHAMO). Dr. Rowe is supported by Canadian Institutes of Health Research (CIHR) as a Tier I Canada Research Chair in Evidence-based Emergency Medicine through the Government of Canada (Ottawa, ON), and Dr. Thiruganasambandamoorthy is supported by the Jump Start Resuscitation Scholarship and currently holds the National New Investigator Salary Award through the Heart and Stroke Foundation of Canada.

Competing interests: None declared.

\section{SUPPLEMENTARY MATERIALS}

To view supplementary material for this article, please visit https://doi.org/10.1017/cem.2018.464

\section{REFERENCES}

1. Thiruganasambandamoorthy V, Taljaard M, Stiell IG, et al. Emergency department management of syncope: need for standardization and improved risk stratification. Intern Emerg Med 2015;10(5):619-27.

2. Moya A, Sutton R, Ammirati F, et al. Guidelines for the diagnosis and management of syncope (version 2009). Task Force for the Diagnosis and Management of Syncope. European Society of, Cardiology, European Heart Rhythm Association, Heart Failure Association, Heart Rhythm Society. Eur Heart 7 2009;30(21):2631-71.

3. Thiruganasambandamoorthy V, Hess EP, Turko E, et al. Outcomes in Canadian emergency department syncope patients - are we doing a good job? 7 Emerg Med 2013;44 (2):321-8.

4. Minhas R, Vogelaar G, Wang D, et al. A prehospital treatand-release protocol for supraventricular tachycardia. CFEM 2015;17(4):395-402.

5. Thiruganasambandamoorthy V, Stiell IG, Sivilotti ML, et al. Risk stratification of adult emergency department syncope patients to predict short-term serious outcomes after discharge (RiSEDS) study. BMC Emerg Med 2014;14:8.

6. Quinn JV, Stiell IG, McDermott DA, et al. Derivation of the San Francisco syncope rule to predict patients with short-term serious outcomes. Ann Emerg Med 2004;43(2): 224-32.

7. Reed MJ, Newby DE, Coull AJ, et al. The ROSE (risk stratification of syncope in the emergency department) study. 7 Am Coll Cardiol 2010;55(8):713-21.

8. Quinn J, McDermott D, Stiell I, et al. Prospective validation of the San Francisco syncope rule to predict patients with serious outcomes. Ann Emerg Med 2006;47(5):448-54.

9. Birnbaum A, Esses D, Bijur P, et al. Failure to validate the San Francisco syncope rule in an independent emergency department population. Ann Emerg Med 2008;52(2): 151-9.

10. Hoskins E. Ontario enhancing emergency services across the province: ensuring people receive faster access to the right care; 2017. Available at: https://news.ontario.ca/ mohltc/en/2017/06/ontario-enhancing-emergency-servicesacross-the-province.html (accessed August 1, 2017). 